\title{
Library of Cationic Polymers Composed of Polyamines and Arginine as Gene Transfection Agents
}

\author{
Nino Zavradashvili, ${ }^{\dagger}$ (i) Can Sarisozen, ${ }^{\dagger}$ Giorgi Titvinidze, ${ }^{\dagger}$ Giuli Otinashvili, ${ }^{\dagger}$ (i) Tengiz Kantaria, ${ }^{\dagger}$ (ㅇ) \\ Davit Tugushi, ${ }^{\dagger}$ Jordi Puiggali, ${ }^{\S}$ Vladimir P. Torchilin, ${ }^{*}, *$ and Ramaz Katsarava ${ }^{*}, \oplus$ \\ ${ }^{\dagger}$ Institute of Chemistry and Molecular Engineering, Agricultural University of Georgia, Kakha Bendukidze University Campus, \# 240 \\ David Aghmashenebeli Alley, 0131 Tbilisi, Georgia \\ ${ }^{\ddagger}$ Center for Pharmaceutical Biotechnology and Nanomedicine, Northeastern University, 360 Huntington Avenue, 02115 Boston, \\ Massachusetts, United States \\ ${ }^{\S}$ Universitat Politècnica de Catalunya, Av. Diagonal 647, E-08028 Barcelona, Spain
}

Supporting Information

ABSTRACT: Combinatorially synthesized materials, especially cationic polymers (CPs), with gene transfection function hold great promise in nanotechnology. However, the main limitations of the existing CPs [such as polyethylenimine (PEI), poly-L-arginine, or polyamidoaminebased dendrimers] as gene transfection agents are high cytotoxicity in the physiological environment. We have developed novel CPs composed of polyamines-endogeneous tetraamine spermine (Spm) and synthetically made triamine $\mathrm{N}$-(2-aminoethyl)-1,3-propanediamine (Apd) for incorporating sec-amino groups and imparting PEI-like structure to the CP backbones. Naturally occurring building blocks such as amino acid arginine (R) was also used for incorporating

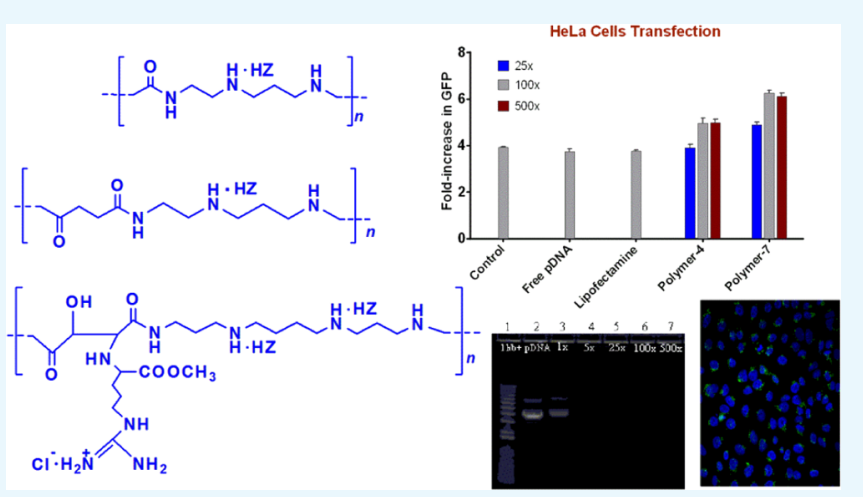
guanidine-groups into the CPs. The cytotoxicity of resulting CPs-polyureas (PUs) and polyamides such as polysuccinamides and R-attached polymalamides was evaluated using murine and human fibroblasts and carcinoma cell lines. The cell compatibility screening revealed that the CPs made of Apd are less cytotoxic compared to Spm-based analogues. From the novel polymer library, total of six polymers were further studied for oligonucleotide (pDNA) complexation and transfection abilities. Highly water-soluble CPs formed nano-sized polyplexes with pDNA at rather low $\mathrm{CP} / \mathrm{pDNA}$ weight ratios and showed less cytotoxicity and higher transfection ability compared to widely used PEI as well as commercially available transfection agents. Furthermore, new CPs showed selective transfection activity toward certain cell lines (4T1, HeLa, NIH3T3, and CCD $27 \mathrm{SK})$, which is important for their potential applications in gene therapy.

\section{INTRODUCTION}

The importance of cationic polymers (CPs) is universally recognized because they exhibit unique biological properties. CPs can form electrostatic complexes with anionic biomolecules including nucleic acids and proteins and are of interest as active biological compound carriers to be used in both gene therapy and biotechnology. In addition, inherent bioactive properties such as antimicrobial, antioxidant, antitumor, and antiinflammatory stimuli responsiveness make CPs more promising for enhanced therapeutic potential. ${ }^{1,2}$ CPs that can be cleared from the body following executing their function, that is biodegradable, look especially valuable.

Intracellular delivery of oligonucleotides is one of the major challenges for the successful gene therapy of serious illnesses including certain viral infections, inherited disorders, and cancer. ${ }^{3}$ Many biological barriers need to be conquered to achieve safe and efficient delivery of nucleic acids to the cytoplasm or nuclei of target cells. The main steps of this promising restorative approach are (i) the protection of the nucleic acid in the circulation from DNase and RNase mediated degradation, (ii) effective extravasation to the target tissue, (iii) successful internalization by the target cells, (iv) endosomal escape and cytoplasmic release of intact oligonucleotide and its subsequent transfer inside the nucleus (in case of pDNAs), and (v) for some applications its integration into the genome of the host cell. Various viral vectors which can mediate gene transfer with high efficiency being used to solve the mentioned tasks. However, the acute immune response, immunogenicity, and insertion mutagenesis have raised serious safety concerns about commonly used viral vectors. ${ }^{4,5}$

CPs have also attracted keen attention because of their lower safety risks and ability to interact with cells effectively. ${ }^{4-12}$

Received: October 28, 2018

Accepted: January 9, 2019

Published: January 28, 2019 
Carefully designed CPs easily form complexes with negatively charged nucleic acids, condensing them into nano-sized structures. $^{13-15}$ However, their low transfection efficacy compared to viral vectors and structure-dependent cytotoxicity limit their wide therapeutic applications. ${ }^{9}$ Therefore, the search of new and more effective CPs as gene carriers remains topical. There is no doubt that for all the pharmacological applications, preference should be given to biodegradable CPs which will be cleared from the body without toxic degradation products after their function is fulfilled. For that, the building blocks used for constructing CPs should be nontoxic and physiologically relevant. From this point of view, the positively charged naturally occurring molecules-polyamines ${ }^{16}$ and $\alpha$-amino acids look especially promising as building blocks for constructing CPs.

Polyamines look suitable for constructing CPs having polyethylenimine (PEI)-like constitution-the terminal primary amino groups could be used for constructing macrochains via step-growth polymerization (polycondensation) and the secondary amino groups for incorporating PEI-like moieties in the polymeric backbones. Among many polyamines, the most widely used for constructing CPs was an endogenous multiamino monomer-tetraamine spermine (Spm). Positively charged L-arginine $(\mathrm{R})$ is another important building block of synthetic CPs as well.

A variety of CPs on the basis of Spm were designed as gene transfection agents via the Michael addition reaction. ${ }^{17-23}$ While efficient gene transfection with less cytotoxicity was obtained with these carriers, they could not degrade back to their original state-biogenic intact Spm, because of their nondegradable or nondirectly connected degradable linkages $\left(N, N^{\prime}\right.$ bis-alkylated derivatives of Spm). The highly charged CPs were also synthesized by conjugation of Spm with oxidized dextran (via aldehyde groups) with subsequent reduction of the obtained amine conjugates (Shiff bases) with $\mathrm{NaBH}_{4}{ }^{24-26}$ The dextran-Spm polycations were used as an efficient nonviral vector for in vitro and in vivo gene transfection. Another types of CPs were synthesized by conjugation of Spm and glutaraldehyde with subsequent reduction of the obtained Shiff bases with $\mathrm{NaBH}_{4}{ }^{27,28}$ However, the polymeric amines obtained by the reduction of the intermediate Shiff-base polymers, similar to the CPs obtained via the Michael addition reaction, ${ }^{17-23}$ do not degrade with releasing free Spm-instead, alkylated Spm of unknown physiological activity is released after the hydrolysis of these polymers.

More promising are polymers releasing free Spm upon biodegradation such as the Shiff base synthesized by polycondensation of Spm and pyruvaldehyde (methylglyoxal) ${ }^{29}$ and the polyamide (PA) composed of Spm and imidazole-4,5dicarboxylic acid. ${ }^{30}$ In the latter case, Spm was incorporated into the CP's backbone through the primary amino groups by means of hydrolysable 1,2-amide bonds. Such kind of chemical structure provided the biodegradation of the polymer under the action of both body fluid ( $\mathrm{pH} 7.4)$ and endolysosome $(\mathrm{pH}$ $5.8),{ }^{30}$ the faster in the latter case. The biodegradability of the polymer could be ascribed to hydrolysis of vicinal (in 1,2 position relative to each other) amide groups due to mutual intramolecular catalysis (anchimeric assistance). ${ }^{31-33}$ The intact free Spm (biogenic amine) is released after such type of biodegradation that is a basic merit of these polymers as compared with the CPs above, ${ }^{17-26}$ in which Spm was incorporated into the backbones with non-hydrolysable alkylated primary amino groups. Hence, the most promising could be considered Spm-based polymers in which Spm is incorporated into the polymeric backbones via the primary amino groups by means of hydrolysable chemical bonds.

R-based CPs have also attracted an attention as transfection agents in recent years owing to findings of Ryser \& Hancock ${ }^{34}$ that only R-rich, and not lysine-rich, histones were able to transport albumin into tumor cells. It was demonstrated that the R-based polymers were significantly more effective in internalizing by tumor cells compared to polymers of similar chain lengths composed of lysine, ornithine, or histidine. Since this finding, guanidine-rich polymers such as poly-R became popular transfection agents. Poly-R, however, showed rather high cytotoxicity that is why several research groups prepared other types of R-enriched carriers ${ }^{35-39}$ that showed a good cellcompatibility but limited transfection activity. Besides, most of these carriers are not biodegradable that means-will not be cleared from the body with a desired rate after executing their function.

Biodegradable R-based (with $\mathrm{R}$ in the backbones) cationic poly(ester amide)s, PEAs, promising as nonviral gene delivery agents, were reported by Yamanouchi et al. ${ }^{40}$ However, the polymers showed a limited water solubility that confines their applications. To increase the water solubility of the R-based ester-polymers, ether links were incorporated into their backbones. A library of R-based ether-ester polymers of various classes which showed an increased water solubility along with an excellent cell-compatibility have been created. ${ }^{41}$

In an alternative approach, $\mathrm{R}$ was attached to the polymeric lateral chains. R-attached biodegradable CPs were obtained by covalent attachment of arginine methyl ester and agmatine (decarboxylated arginine) to PEAs containing lateral carboxyl groups; ${ }^{42}$ these polymers, however, were insoluble in water that restricted their application as transfection agents. In an another approach, R-attached biodegradable cationic poly(ethylene malamide) was obtained according to one-pot procedure by in situ covalent attachment of arginine methyl ester to intermediary poly(ethylene epoxy-succinamide). ${ }^{43}$ The CP showed an excellent cell compatibility and satisfactory transfection activity.

In this study, Spm and R were selected as building blocks for synthesizing new library of CPs. Another polyamine-a synthetic triamine with shorter polymethylene chains- $-\mathrm{N}-(2-$ aminoethyl)-1,3-propanediamine (Apd) was also included in the library plan for constructing the PEI-like backbones of CPs for a comparative study. For synthesizing the new CPs, the solution active polycondensation (SAP) method ${ }^{44,45}$ was selected, and two classes of the CPs-polyureas (PUs) and PAs were obtained. At that two types of PAs containing vicinal amide groups-polyamine based unsubstituted polysuccinamides (PSuAs) and polyamine based R-substituted polymalamides (RPAs) were synthesized and studied. The latter were obtained via one-pot/two-step procedure by covalent attachment of R-methyl ester dihydrochloride (RMeC) to the intermediate polyamine-based epoxy-PSuAs (EPAs), similar to the procedure reported in ref 43 for the synthesis of $\mathrm{R}$ substituted poly(ethylene malamide).

\section{RESULTS AND DISCUSSION}

Monomers. Polyamines-tetrafunctional Spm and trifunctional Apd were transformed into the salt monomers SpmT4, SpmC4, ApdT3, and ApdC3 (Scheme S1), which were subsequently used as key bisnucleophilic monomers for the synthesis of a small library of polymers, due to the following reasons: 
Scheme 1. Structure of the New Spm and Apd-Based Polymers: PUs, PSuAs, Intermediate EPAs, and RPAs ${ }^{a}$<smiles>CC(C)(C)NCCNCCCNCCCNC(=O)C(C)(C)C</smiles>

1SpmT or $1 \mathrm{SpmC}$

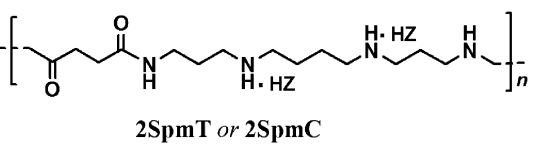<smiles>[Z]C(CCNCCCNC(=O)C1OC1C(=O)C(C)(C)C)NCCNCCC(C)(C)C</smiles>

ESpmT or ESpmC

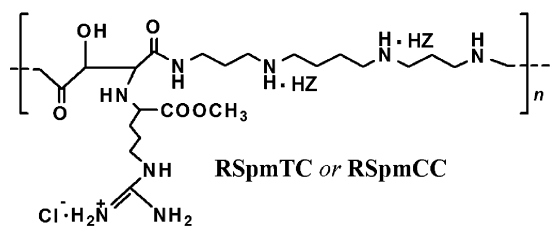<smiles>[R2]CCNCCNC(=O)C(C)(C)C</smiles>

1ApdT or 1ApdC

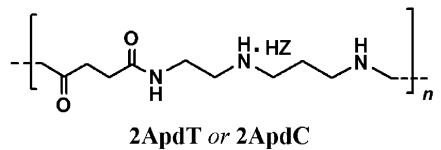<smiles>[Z2]CCNCCNC(=O)C1CC(C)C(=O)O1</smiles>

EApdT or EApdC

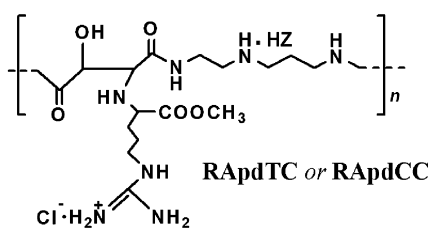

$\mathrm{HZ}=\mathrm{H}_{3} \mathrm{C}-\longrightarrow-\mathrm{SO}_{3} \mathrm{H}(\mathbf{T}) \quad$ or $\quad \mathrm{HCl}(\mathbf{C})$

${ }^{a}$ All polymers synthesized were in salts forms-either $p$-toluenesulfonates $(\mathrm{T})$ or hydrochlorides $(\mathrm{C})$; in case of RPAs one hydrochloric acid molecule (C) belongs to the residue of R-methyl ester, $\mathrm{RMeC}$.

1. The nucleophilic reactivity of the primary amino groups in the polyamines is higher compared to the secondary amino groups which are sterically more hindered. Hence, the polyamines could be considered as potentially bifunctional monomers capable to form linear (at least branched but soluble) polymers when observing the precautions during the polycondensation reaction with bis-electrophiles. The difference in reactivity of the primary and secondary amino groups could be increased by salt formation: after adding an organic base (a proton acceptor) that is necessary to carry out the polycondensation, protons are more easily removed from the primary amino groups owing to lower basicity as compared with the secondary amino groups.

2. Spm is a hygroscopic solid, and Apd is a liquid productboth less convenient to manipulate. All the salts made of them are solids and less hygroscopic products more convenient for manipulations. Surprisingly, hydrochlorides were found less hygroscopic than $p$-toluenesulfonates-no weight gain was observed after a $180 \mathrm{~min}$ exposure under atmospheric conditions (Figure S1). The structures of the salt monomers, depicted in Scheme S1, were confirmed by elemental analysis and ${ }^{1} \mathrm{H}$ NMR spectroscopy (see Supporting Information).

R-methyl ester dihydrochloride (RMeC) used for synthesizing RPAs was synthesized as reported previously. ${ }^{43}$

Activated diesters such as di-p-nitrophenyl carbonate (NC), $\mathrm{NSu}$, and $\mathrm{N} t \mathrm{ES}$ (see Scheme S2) were used as bis-electrophilic monomers for the polymers synthesis due to the following reasons:
1. The activated diesters are soft acylating agents and it was expected that they allow a higher selectivity toward the primary and secondary amino groups. This could farther increase a probability of the chain growth reaction through the primary amino groups, thus leading to CPs close to a linear structure (at least branched but soluble).

2. The activated carbonate NC was used for diisocyanate free synthesis of PUs via SAP with fatty diamines as reported in ref 46 . The method was applied to the synthesis of PUs on the basis of Spm and Adp because diisocyanates of these polyamines are unavailable.

3. The activated diester NSu was used for synthesizing biodegradable PAs of 1,2-dicarboxylic acid-PSuAs. These kinds of polymers are unavailable through traditional high- and low-temperature polycondensations, and they can be obtained via SAP only using soft acylating agents-activated diesters of succinic acid. ${ }^{47}$

4. The activated diester $\mathrm{N} t \mathrm{ES}$ was used for synthesizing biodegradable PAs of 1,2-dicarboxylic acid (malic acid) with covalently attached R-methyl ester hydrochloride $(\mathrm{RMeC})$ via one-pot/two-step procedure as reported in ref 43.

The characteristics of the used activated diesters NC, NSu, and $\mathrm{N} t \mathrm{ES}$ were in accordance with the published data.

The activated diesters of 1,2-diacids- $\mathrm{NSu}$ and $\mathrm{N} t \mathrm{ES}$ were selected with the purpose to synthesize PAs with 1,2-amide bonds in the backbones which are hydrolyzed due to mutual intramolecular catalysis-so called "anchimeric assistance". $31-33$ 
Table 1. Summary of Characterization Parameters of the CPs ${ }^{b}$

\begin{tabular}{|c|c|c|c|c|c|c|c|c|}
\hline \multirow[b]{2}{*}{ sample \# } & \multirow[b]{2}{*}{$\mathrm{CP}$} & \multirow[b]{2}{*}{$\begin{array}{l}\text { class of } \\
\text { polymer }\end{array}$} & \multirow[b]{2}{*}{ empirical formula (MM) } & \multirow[b]{2}{*}{$\begin{array}{l}\text { yield, } \% \text { before/after } \\
\text { dialysis }^{a}\end{array}$} & \multicolumn{3}{|c|}{ molecular weight characteristics } & \multirow[b]{2}{*}{$\begin{array}{l}\text { tested for transfection } \\
\text { activity }\end{array}$} \\
\hline & & & & & $\begin{array}{l}M_{\mathrm{n}} \\
(\mathrm{Da})\end{array}$ & $\begin{array}{l}M_{\mathrm{w}} \\
(\mathrm{Da})\end{array}$ & dispersity, $\oslash$ & \\
\hline 1 & $1 \mathrm{SpmT}$ & $\mathrm{PU}$ & $\mathrm{C}_{25} \mathrm{H}_{40} \mathrm{~N}_{4} \mathrm{O}_{7} \mathrm{~S}_{2}$ (572.74) & $98 / 38$ & 5771 & 22229 & 3.85 & - \\
\hline 2 & $1 \mathrm{SpmC}$ & PU & $\mathrm{C}_{11} \mathrm{H}_{26} \mathrm{~N}_{4} \mathrm{OCl}_{2}$ (265.18) & $100 / 40$ & 6632 & 25454 & 3.84 & - \\
\hline 3 & 1ApdT & PU & $\mathrm{C}_{13} \mathrm{H}_{21} \mathrm{~N}_{3} \mathrm{O}_{4} \mathrm{~S}$ (315.39) & $98 / 45$ & 773 & 1168 & 1.51 & - \\
\hline 4 & 1ApdC & $\mathrm{PU}$ & $\mathrm{C}_{6} \mathrm{H}_{14} \mathrm{~N}_{3} \mathrm{OCl}(179.65)$ & $100 / 40$ & 1109 & 4403 & 3.97 & + \\
\hline 5 & $2 \mathrm{SpmT}$ & PSuA & $\mathrm{C}_{28} \mathrm{H}_{44} \mathrm{~N}_{4} \mathrm{O}_{8} \mathrm{~S}_{2}(628.80)$ & $94 / 47$ & 1948 & 3687 & 1.89 & - \\
\hline 6 & $2 \mathrm{SpmC}$ & PSuA & $\mathrm{C}_{14} \mathrm{H}_{30} \mathrm{~N}_{4} \mathrm{O}_{2} \mathrm{Cl}_{2}$ (321.87) & $97 / 45$ & 595 & 1843 & 3.09 & - \\
\hline 7 & 2ApdT & PSuA & $\mathrm{C}_{16} \mathrm{H}_{25} \mathrm{~N}_{3} \mathrm{O}_{5} \mathrm{~S}(371.45)$ & $100 / 50$ & 2417 & 4741 & 1.96 & + \\
\hline 8 & 2ApdC & PSuA & $\mathrm{C}_{9} \mathrm{H}_{18} \mathrm{~N}_{3} \mathrm{O}_{2} \mathrm{Cl}(235.71)$ & $95 / 52$ & 2809 & 8340 & 2.97 & + \\
\hline 9 & RSpmTC & RPA & $\begin{array}{l}\mathrm{C}_{35} \mathrm{H}_{59} \mathrm{~N}_{8} \mathrm{O}_{11} \mathrm{~S}_{2} \mathrm{Cl} \\
\quad(867.47)\end{array}$ & $100 / 57$ & 2853 & 25945 & 9.09 & - \\
\hline 10 & RSpmCC & RPA & $\mathrm{C}_{21} \mathrm{H}_{41} \mathrm{~N}_{8} \mathrm{O}_{5} \mathrm{Cl}_{3}$ (591.96) & $99 / 67$ & 788 & 2484 & 3.15 & + \\
\hline 11 & RApdTC & RPA & $\mathrm{C}_{23} \mathrm{H}_{37} \mathrm{~N}_{7} \mathrm{O}_{8} \mathrm{SCl}(607.10)$ & $100 / 58$ & 1015 & 1519 & 1.49 & + \\
\hline 12 & RApdCC & RPA & $\mathrm{C}_{16} \mathrm{H}_{30} \mathrm{~N}_{7} \mathrm{O}_{5} \mathrm{Cl}_{2}(435.91)$ & $98 / 65$ & 956 & 7748 & 8.10 & + \\
\hline
\end{tabular}

Polymers. Two classes of polyamine-based heterochain polymers were synthesized via SAP within the framework of presented study. Initially, taking into account the polyfunctional nature of Spm and Apd, and problematic character of the synthesis of linear (at least branched but soluble) heterochain polymers using for the chain growth primary amino groups of the polyamines, we have selected the synthesis of PUs via SAP of the Spm and Apd (Scheme S3): the only interaction of activated carbonate such as $\mathrm{NC}$ with primary amino groups proceeds via the intermediate isocyanate (Scheme S3) and results in the formation of the urea links after the interaction with another primary amino group; ${ }^{46}$ the interaction of the intermediate isocyanate with secondary amino groups cannot be excluded completely but the rate of this reaction should be much lower due to higher steric hindrance. The interaction of NC with secondary amino groups represents a "dead-end" reaction, which does not lead to the formation of the urea link. We supposed that this had to farther increase the probability of the formation of soluble polymers after SAP of NC with the salts of polyamines. The obtaining soluble PUs ( $1 \mathrm{SpmT}$ or $1 \mathrm{SpmC}$, and 1 ApdT or 1 ApdC, Scheme 1) confirmed this assumption. After the successful synthesis of the soluble PUs, we have synthesized soluble PSuAs (2SpmT or $2 \mathrm{SpmC}$, and $2 \mathrm{ApdT}$ or $2 \mathrm{ApdC}$, Scheme 1) under the similar reaction conditions (Scheme S4). Finally, we have synthesized the RPAs (RSpmTC or RSpmCC, and RApdTC or RApdCC, Scheme 1) for incorporating the guanidine lateral groups into the macromolecules of the CPs. These RPAs were prepared according to one-pot/two-step procedure (Scheme S5) as reported previously for the EPAs composed of 1,2-ethylenediamine. ${ }^{43}$ The intermediate Spm or Apd-based EPAs (ESpmT or ESpmC, and EApdT or EApdC in Scheme 1) were synthesized by polycondensation of $\mathrm{N} t \mathrm{ES}$ with the salt monomers (Step 1 in Scheme S5).

The detailed protocols of the synthesis of CPs are given in the Supporting Information. All the polymers were synthesized in dimethyl sulfoxide solution at a monomer concentration 1.2 $\mathrm{mol} / \mathrm{L}$ in the presence of $2 \mathrm{~mol}$ (per $1 \mathrm{~mol}$ of a salt monomer) of triethylamine (TEA) used as an acid ( $\mathrm{HCl}$ or $\mathrm{Tos} \mathrm{OH})$ acceptor. The polycondensation of the salt monomers with $\mathrm{NC}$ and $\mathrm{NSu}$ was started at rt. At this temperature, the SAP reactions were carried out heterogeneously even after $3 \mathrm{~h}$ stirring. Afterward, the reaction temperature was gradually (in a timeframe of $2 \mathrm{~h}$ to avoid crosslinking) increased up to $80^{\circ} \mathrm{C}$ and proceeded for additional $16 \mathrm{~h}$. Under these conditions, all the reaction mixtures were homogenized except to the mixtures of chloride salt monomers SpmC4 and ApdC3 with NC-the synthesis of the PUs 1 SpmC and 1ApdC was carried out heterogeneously until the end of the polycondensation. The polycondensation reaction with participating $\mathrm{N} t \mathrm{ES}$ was also started at $\mathrm{rt}$ and homogeneous reaction was proceeded for total $20 \mathrm{~h}$. In this case, there was no need to elevate the reaction temperature either for the homogenization reaction or for its acceleration-the epoxymonomer $\mathrm{N} t \mathrm{ES}$ is more active as compared with activated diesters of regular dicarboxylic acids due to intramolecular catalytic influence of the oxygen atom in $\alpha$-position from carbonyl groups. ${ }^{48}$ This was the first step of the one-pot procedure resulting in the intermediary EPAs such as ESpmT, ESpmC, EApdT, and EApdC (Scheme 1). At the second step (Scheme S5), the intermediary EPAs were interacted in situ with $\mathrm{RMeC}$ at $60{ }^{\circ} \mathrm{C}$ for $24 \mathrm{~h}$ resulting in the goal RPAs such as RSpmTC or RSpmCC, and RApdTC or RApdCC (Scheme 1). The resulting RPAs also represent biodegradable PAs of 1,2dicarboxylic acid-polymalamides containing R-methyl ester attached covalently via $\alpha$-amino groups to the malamide residues in $\beta$-position (Scheme 1). Degree of transformation of EPAs determined by ${ }^{1} \mathrm{H}$ NMR was within $60-70 \mathrm{~mol} \%$ (see Supporting Information) that satisfactorily coincide with reported value ( $75 \%$ determined using IR spectrometry). ${ }^{43}$

The obtained CPs were purified by $4 \mathrm{~h}$ dialysis using tubing with 1000 Da MWCO followed by freeze-drying. The yields (before and after dialysis) and molecular weight characteristics (after dialysis) of the CPs are summarized in Table 1. The structures of the CPs were confirmed by ${ }^{1} \mathrm{H}$ NMR analysis (see Supporting Information). All the obtained CPs are hygroscopic; they are well soluble in water and easily form solutions of 200 $\mathrm{mg} / \mathrm{mL}$ concentration (used as stock solutions in biological experiments).

The molecular weight characteristics of the obtained new library of CPs (in total 12 polymers, Scheme 1) $-M_{\mathrm{w}}, M_{\mathrm{n}}$, and $M_{\mathrm{w}} / M_{\mathrm{n}}$ (dispersity, $Ð$ ) measured using the gel permeation chromatography (GPC) in the hexafluoroisopropanol (HFIP)/ $\mathrm{CF}_{3} \mathrm{COONa}$ system after dialysis are reported in Table 1 . The weight average molecular weights $\left(M_{\mathrm{w}}\right)$ of most of the obtained CPs are within 1200-7700 Da. The dispersity $Đ$ of some (4 of 12) of the CPs was within 1.50-1.96 that is typical for polymers obtained via step growth polymerization (polycondensation) 
a)
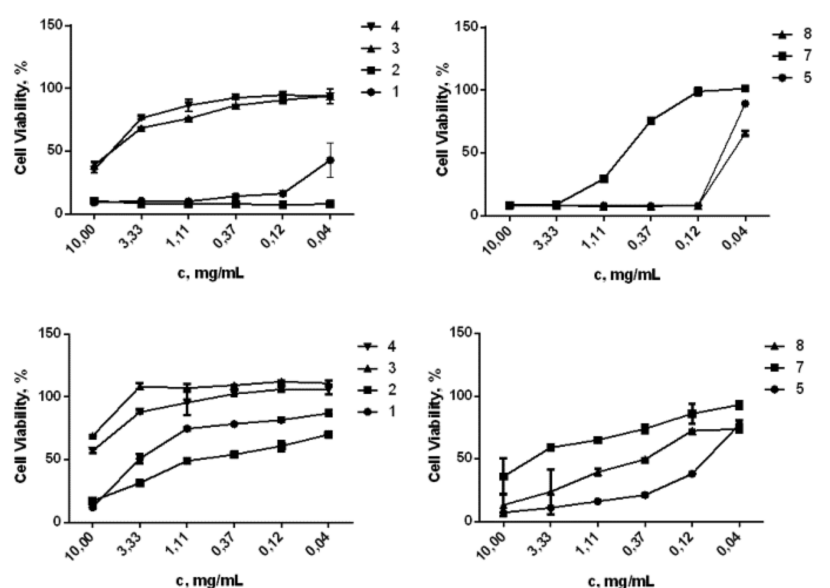

c, $\mathrm{mg} / \mathrm{mL}$

c)
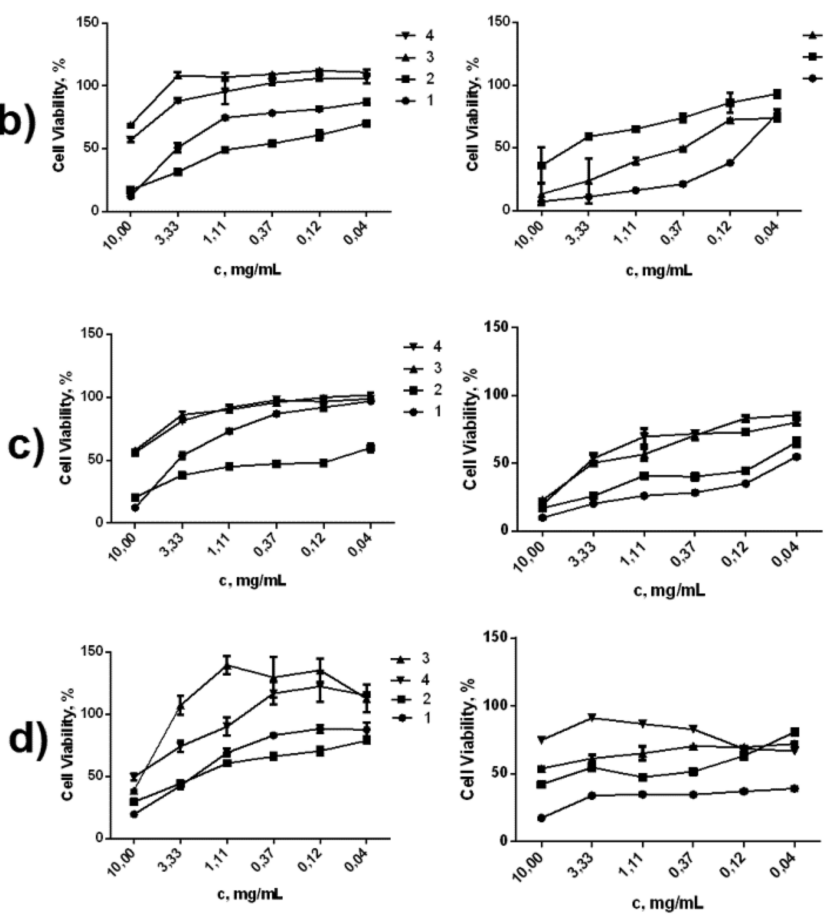

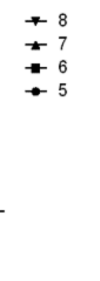

+8
+7
+6
-5
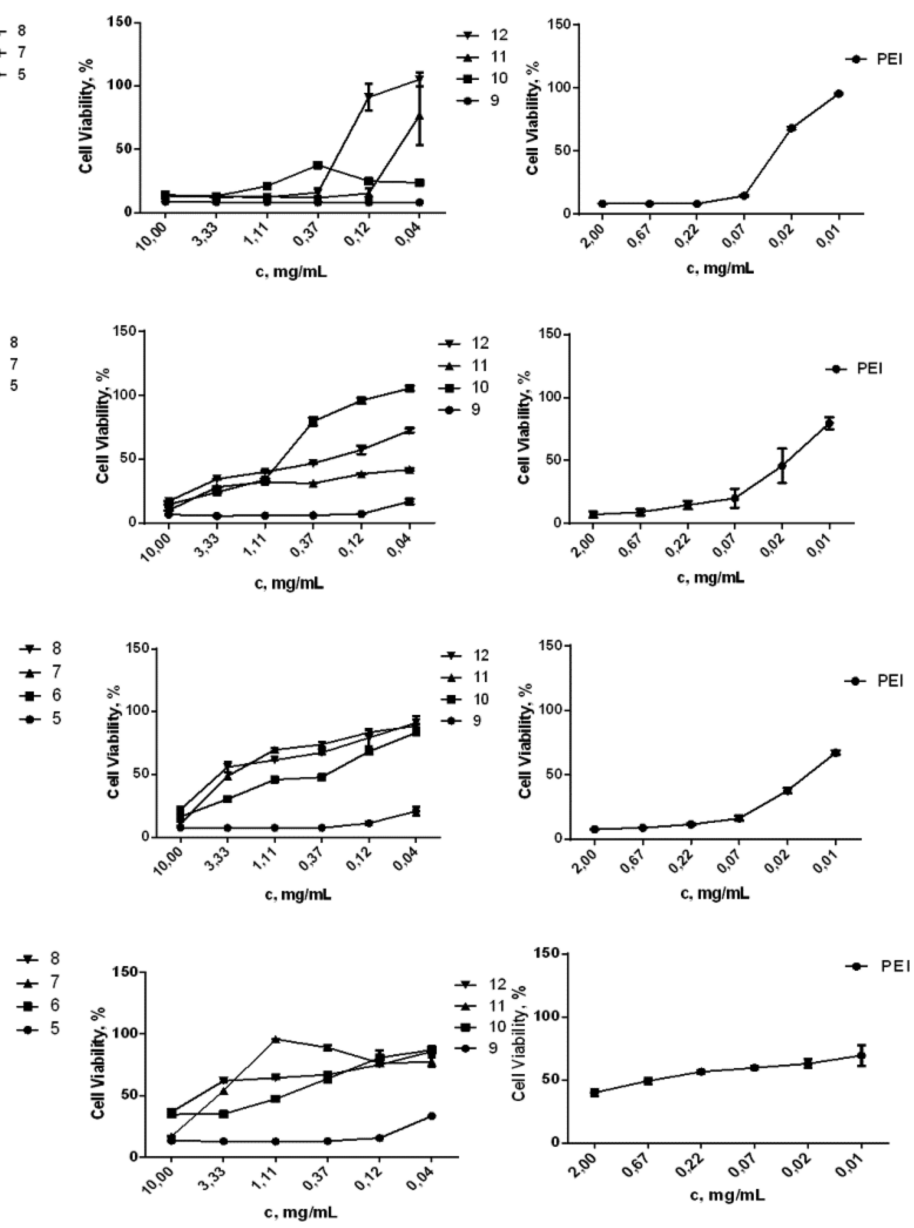

Figure 1. Cell viability of (a) HeLa, (b) 4T1, (c) CCD 27SK cells after $24 \mathrm{~h}$, and (d) NIH3T3 cells after $48 \mathrm{~h}$ with the new CPs within a concentration range $10.00-0.04 \mathrm{mg} / \mathrm{mL}$. The numbers on graphs correspond to the polymers numbers in Table 1 . Cell viability with PEI in a concentration range $2.00-0.01 \mathrm{mg} / \mathrm{mL}$ is also given for a comparison. The concentration range for PEI is limited by its solubility in water.

and could speak the polymer structure is close to linear. $Đ$ of other CPs was within 2.96-8.93, which could indicate that these polymers are branched. $M_{\mathrm{w}}$ of these polymers are especially high-up to 25900 , which is also a strong indication that the polymers are branched. Running ahead, it should be noted that the CPs with molecular weights $\left(M_{\mathrm{w}}\right)$ above $20000 \mathrm{Da}$ showed the highest cytotoxicity and were not selected for transfection study. The observed molecular weights $\left(M_{\mathrm{w}}\right)$ of nontoxic polymers are within $1200-7700 \mathrm{Da}$. It has to be noted here that molecular weights of heterochain polymers measured in HFIP/ $\mathrm{CF}_{3} \mathrm{COONa}$ system are 2-3 times lower than molecular weights determined in dimethylformamide (DMF). ${ }^{49}$ Our attempt to determine the molecular weights of the CPs using the GPC in DMF failed because the polymers were irreversibly bound to Styragel columns.

In Vitro Cytotoxicity Experiments. Prior to investigating the transfection ability of the newly synthesized CPs, we have evaluated their cytotoxicity to select the candidates showing high cell compatibility. The studies were performed using two cancer cell lines, one human (HeLa, human cervical adenocarcinoma cell line) and one murine (4T1, mouse mammary gland breast cancer cell line). In addition, two noncancerous cell lines, one human (CCD 27SK, human skin fibroblasts) and one murine (NIH3T3, mouse embryo fibroblasts), were added to the study to investigate a wide range of possible working space. The concentration range of the CPs was $10-0.04 \mathrm{mg} / \mathrm{mL}$. As seen from the results (Figure 1), the cellular metabolic activity (considering all cell lines used) is significantly higher for polymers (for numbering CPs see Table 1) \#4 and \#7 with HeLa cells, polymers \#4, \#7, and \#10 with 4T1 cell lines, \#4 and \#10 with NIH3T3 and \#4, \#7, \#11, and \#12 with CCD 27SK cells. Polymer \#9 appeared to be significantly toxic with all cell lines used.

It is known that the cationic molecules or particles are associated with cytotoxic effects. ${ }^{50}$ For example, cationic lipids containing tertiary or quaternary amines result in high cytotoxicity caused by the interference with critical enzymes such as protein kinase C. ${ }^{51}$ However, the toxicity can be partly weakened by delocalizing the positive charge of the cationic group-aromatic heterocyclic ring (e.g. pyridine) or guanidine was found to be significantly less toxic compared to the ammonium functionality, especially quaternary ammonium functionality. ${ }^{50}$ Yingyongnarongkul et al. ${ }^{52}$ synthesized guanidine-containing transfection agents among a library of different cationic lipids and demonstrated that these compounds were safer. It has to be emphasized that all the R-based biodegradable polymers mentioned above ${ }^{40,41,43}$ were found to be nontoxic for the tested concentration range (up to $2 \mathrm{mg} / \mathrm{mL}$ ) and, in some cases, even slightly enhanced cell growth.

Our results also emphasize the different response of different cell types to the selection of CPs. Here, we could see the advantages of the library-based development approach as where one of the CPs failed in terms of toxicity, the other types of CPs deemed to be safe. Therefore, we have selected polymers \#3, \#4, 
Table 2. Cell Viability Values (\%) of Corresponding CPs at Different WR Ratios CPs/pDNA

\begin{tabular}{|c|c|c|c|c|c|c|c|c|c|c|c|c|}
\hline \multirow{4}{*}{ Cell line } & \multicolumn{12}{|c|}{ Polymer sample } \\
\hline & \multirow{2}{*}{\multicolumn{2}{|c|}{$\begin{array}{c}1 \mathrm{ApdC} \\
\# 4\end{array}$}} & \multirow{2}{*}{\multicolumn{2}{|c|}{$\begin{array}{c}2 \mathrm{ApdT} \\
\$ 7\end{array}$}} & \multirow{2}{*}{\multicolumn{2}{|c|}{$\begin{array}{c}2 \mathrm{ApdC} \\
\# 8\end{array}$}} & \multirow{2}{*}{\multicolumn{2}{|c|}{$\begin{array}{c}\text { RSpmCC } \\
\# 10\end{array}$}} & \multirow{2}{*}{\multicolumn{2}{|c|}{$\begin{array}{c}\text { RApdTC } \\
\# 111\end{array}$}} & \multirow{2}{*}{\multicolumn{2}{|c|}{ RApdCC }} \\
\hline & & & & & & & & & & & & \\
\hline & $100 x^{\star}$ & $500 x$ & $100 x$ & $500 x$ & $100 x$ & $500 x$ & $100 x$ & $500 x$ & $100 x$ & $500 x$ & $100 x$ & $500 x$ \\
\hline HLLa & 95 & 90 & 100 & 80 & 60 & 10 & 30 & 40 & 75 & 15 & 90 & 20 \\
\hline $4 \mathrm{TI}$ & 105 & 105 & 90 & 80 & 70 & 55 & 100 & 80 & 45 & 35 & 60 & 50 \\
\hline $\mathrm{NIH} 3 \mathrm{TT}_{3}$ & 115 & 115 & 75 & 75 & 65 & 80 & 90 & 65 & 80 & 90 & 80 & 75 \\
\hline CCD 27SK & 100 & 100 & 90 & 75 & 75 & 70 & 80 & 50 & 95 & 75 & 90 & 75 \\
\hline
\end{tabular}

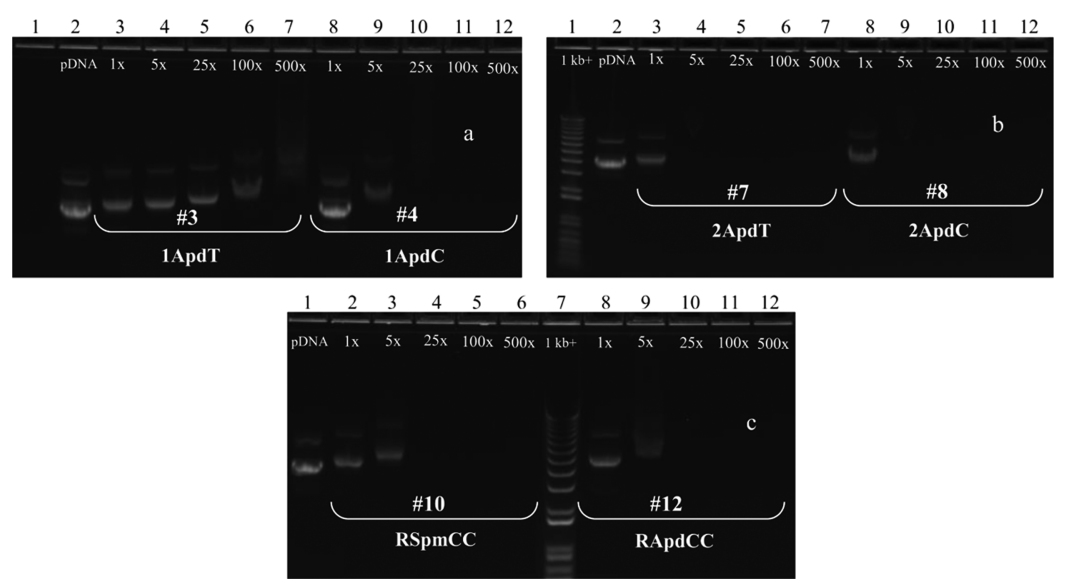

Figure 2. Agarose (0.8\%) gel electrophoresis of new CPs/pDNA complexes: (a) lane 2-naked pDNA. Lanes 3-7: polymer \#3/pDNA WRs (designated as $1 \times, 5 \times$ etc.), lanes 8-12-polymer \#4/pDNA. (b) Lane 1-1 kb+ DNA ladder, lane 2-naked pDNA. Lanes 3-7-polymer \#7/ pDNA, lanes 8-12-polymer \#8/pDNA. (c) Lane 1-naked pDNA. Lanes 2-6: polymer \#10/pDNA, lane 7-1 kb+ DNA ladder, lanes 8-12polymer \#12/pDNA.

\#7, \#8, \#10, \#11, and \#12 for the further biological studies. It should also be noted that from every family of CPs, at least two candidates were selected (\#3 and \#4 from PUs, \#7 and \#8 from PSuAs, \#10,\#11 and \#12 from RPAs) to have a higher possibility of carrying more CPs to the following steps of evaluation. Table 2 also indicates the cell viability values of the corresponding polymers at different weight ratios (WR) in the complexes $\mathrm{CP} /$ pDNA as heat map to better visualize the cytotoxicity pattern of the CPs. The CP \#3 (1ApdT) is omitted because it did not form complexes with pDNA (see Figure 2).

Polymer/DNA Complex Formation Study. The CP/ pDNA complex formation study for selected polymers was accomplished using gel-retardation assay according the procedure given in the Experimental Section. As can be seen from the results (Figure 2), despite the favorable cytotoxicity profile, polymer \#3 could not form complexes with pDNA. Polymer \#4 was able to form complexes only at WR of $25 \times$ and above. In case of polymers \#7 and \#8, the complex formation starts at a lower WR of $5 \times$, while polymers \#10-12 were able to bind pDNA and form complexes starting with a WR of $25 \times$; polymer \#11 also forms complexes with pDNA (not shown in Figure 2 but given in Table 3 ). Here, we were again able to have a selection choice due to step-by-step elimination of a CP library. Results highlight that there is no one-fits-for-all solution to develop a CP that will have a favorable cytotoxicity profile among a wide selection of cell types and still able to effectively complex genetic material.

DNase I Digestion Assay. To further investigate if the pDNA encapsulation into the selected formulations protects it from the nuclease activity which otherwise can cause inactivation of pDNA within minutes of administration, we performed the DNase digestion assay. pDNA must be protected from intracellular degradation prior to reaching its final
Table 3. Particle Size and Zeta Potential of the CPs/pDNA Complexes with Different WRs

\begin{tabular}{|c|c|c|c|c|c|c|}
\hline \multirow[b]{2}{*}{$\begin{array}{c}\mathrm{CP} \\
\text { sample \# }\end{array}$} & \multirow[b]{2}{*}{ WR } & \multicolumn{3}{|c|}{ size of complexes $\mathrm{CP} / \mathrm{pDNA}$} & \multicolumn{2}{|c|}{$\begin{array}{c}\text { zeta potential of } \\
\text { complexes } \\
\mathrm{CP} / \mathrm{pDNA}\end{array}$} \\
\hline & & $\begin{array}{c}\text { eff. diam. } \\
(\mathrm{nm})\end{array}$ & SD & polydispersity & $\mathrm{mV}$ & $\mathrm{SD}$ \\
\hline \multirow[t]{3}{*}{4} & $25 x$ & 212.8 & 1.0 & 0.19 & 0.01 & 0.00 \\
\hline & $100 \times$ & 50.5 & 1.7 & 0.28 & 9.44 & 1.35 \\
\hline & $500 \times$ & 48.5 & 2.6 & 0.31 & 51.34 & 5.27 \\
\hline \multirow[t]{3}{*}{7} & $25 \times$ & 117.0 & 5.7 & 0.36 & 22.60 & 3.40 \\
\hline & $100 \times$ & 77.5 & 6.6 & 0.48 & 24.51 & 1.23 \\
\hline & $500 \times$ & 78.0 & 4.6 & 0.40 & 40.20 & 5.05 \\
\hline \multirow[t]{3}{*}{8} & $25 \times$ & 59.0 & 2.2 & 0.20 & 0.00 & 0.00 \\
\hline & $100 \times$ & 56.5 & 2.9 & 0.37 & 19.15 & 3.15 \\
\hline & $500 \times$ & 65.7 & 2.0 & 0.38 & 31.19 & 3.85 \\
\hline \multirow[t]{3}{*}{10} & $25 x$ & 312.0 & 2.4 & 0.13 & 8.11 & 1.59 \\
\hline & $100 \times$ & 44.0 & 1.3 & 0.16 & 24.14 & 0.66 \\
\hline & $500 \times$ & 38.8 & 1.3 & 0.27 & 57.43 & 12.07 \\
\hline \multirow[t]{3}{*}{11} & $25 \times$ & 84.3 & 5.4 & 0.66 & 34.11 & 1.91 \\
\hline & $100 \times$ & 75.1 & 3.5 & 0.42 & 34.09 & 6.41 \\
\hline & $500 \times$ & 72.7 & 5.5 & 0.32 & 44.54 & 0.98 \\
\hline \multirow[t]{3}{*}{12} & $25 x$ & 68.1 & 5.1 & 0.80 & 23.34 & 1.20 \\
\hline & $100 \times$ & 47.2 & 3.5 & 0.45 & 32.53 & 4.33 \\
\hline & $500 \times$ & 38.0 & 3.8 & 0.41 & 35.035 & 5.03 \\
\hline
\end{tabular}

destination within the nucleus. The data given in Figure 3 show that the naked pDNA was completely degraded when exposed to nuclease, while polymer \#10 formed the protective shield for pDNA at WR of $100 \times$ and $500 \times$. Polymer \#4 protected the pDNA at WR 500×. Polymers \#7 and \#8 were able to protect the pDNA from degradation at both WR tested (100X and $500 \times)$. 

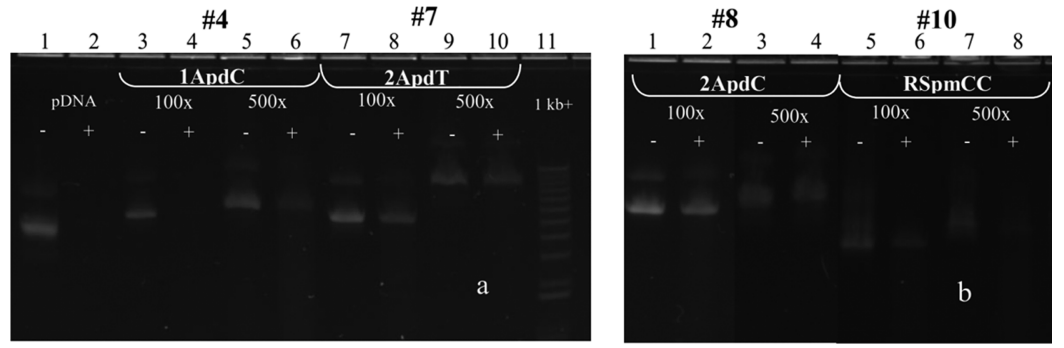

Figure 3. Agarose (0.8\%) gel electrophoresis of DNase I digestion assay. (a) Lane 1 naked pDNA (pEGFP-N1), lane 2 pDNA upon the addition of DNase I as a control. Lane 3, 5, 7, 9-100× and 500× WR of polymer/pDNA complexes. Lane 4, 6, 8, 10-the same complexes treated with DNase I. (b) Lane 1, 3, 5, 7-100× and 500× WR of polymer/pDNA complexes. Lane 4, 6, 8, 10- the same complexes treated with DNase I.

Characterization of Polyplexes. The size and zeta potential of the complexes obtained were analyzed by the quasi-electric light scattering (QELS). As can be seen from the results given in Table 3 , all complexes are nano-sized (38-312 $\mathrm{nm}$ ) and have a positive surface charge. High zeta potential values are also a strong indicative of electrostatic stabilization of the nanocomplexes. Although the complexes for polymers \#7 and \#8 were formed at WR $5 \times$ (Figure 3 ), but the complex size and zeta potential results received only from WR $25 \times$. It should also be noted that for the tested complexes the zeta potential values are increasing with the increased $W R$ of $C P$ in the complex (Figure 4). This suggests that following complete

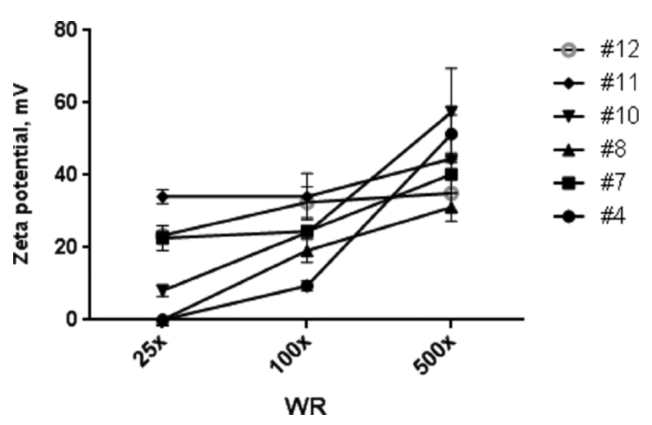

Figure 4. Zeta potential vs WR of new CPs/pDNA complexes.

encapsulation of pDNA by corresponding CPs, the excess polymer chains (positively charged) aligning themselves on the outer surface of the nanocomplexes and cover it layer by layer, hence increasing the overall positive charge.

Cellular Uptake of the Polymer/pDNA Complexes. The ability of CPs to deliver pDNA was investigated by flow cytometry analysis using eGFP-encoding pDNA. Transfection experiments of selected CPs were carried out with 4T1, HeLa, NIH3T3, and CCD 27SK cells. The CPs which are able to form the complexes with pDNA were selected based on the cytotoxicity, complex formation, and pDNA protection results. The CPs and WRs resulted in $90 \%$ and higher cell viability values were selected for testing (Table 2).

As can be seen from the Figure 5, polymer \#10 with WR of $100 \times$ and $500 \times$ reveals a higher transfection efficiency as compared to the other polymers and commercially available transfection agent-DharmaFECT, in murine cell lines. Cells without any additions (controls) and with a free plasmid DNA addition showed negligible transfection in all cases. A significant increase in the percent of eGFP-positive cells was observed with increasing WR at almost all cases. On the other hand, for HeLa human cancer cell line polymer \#7 resulted in better transfection compared to \#4. More importantly, polymers \#4 and \#7, which both transfected the HeLa cells efficiently, did not cause any eGFP expression on noncancerous human skin fibroblast cell line. This selective transfection ability profiles strongly emphasizes the importance of selecting correct polymer for the correct application. By developing a library of novel CPs, we were able to identify the individual polymers for find the balance between cytotoxicity, complex formation, pDNA protection, and effective transfection for different types of cell lines (Table 4).

Confocal Microscopy Study. eGFP expression of HeLa cells following transfection by polymer \#4 and \#7 was also monitored by confocal microscopy. A Zeiss Confocal LSM 700 was used to obtain DIC and fluorescent images of cells (Figure 6). It should be noted that, for successful transfection, several barriers must be overcome even in in vitro settings. First, the pDNA must be delivered inside the cells. For that, complex formation with positively charged CPs was proven to be significantly beneficial. However, following internalization, the CPs must be able to release their pDNA cargo inside the cytoplasm in its intact form, rather than forming a strong complex that is not able to detach from pDNA. Flow cytometry and microscopy studies support each other and strongly indicate that the carefully selected CPs from a small library of polymers were able to provide all the required properties as effective transfection agents.

\section{CONCLUSIONS}

A library of new highly water-soluble CPs were designed and synthesized on the basis of naturally occurring building blocks such as amino acid arginine (R), endogeneous tetraamineSpm and synthetically made triamine Apd. Twelve new polyamine-based CPs of two classes-PUs and PAs were synthesized via SAP. The cytotoxicity of all 12 CPs toward different cell lines was evaluated to select low-toxic (90\% and more cell viability) candidates for in vitro transfection studies. A further screening of the selected CPs was done based on the complex formation with pDNA to evaluate their potential as the nucleic acid carriers. The samples of the CPs which formed positively charged (zeta potentials $\leq+57.4 \mathrm{mV}$ ) stable nanocomplexes CPs/pDNA (38.0-312.0 nm) at low WR $(\mathrm{CPs} / \mathrm{pDNA} 5 \times$ to $25 \times$ ) were considered as nanocarrier candidates and selected for the transfection experiments on human and murine cell lines. The ability of selected CPs to deliver pDNA was further investigated by flow cytometry analysis and confocal microscopy study using eGFP-encoding pDNA. This systematic approach to evaluate the synthesized polymers allowed us to perform a step-by-step elimination process for identifying the most effective polymers and their potential as gene carriers. Studies are designed to support each 

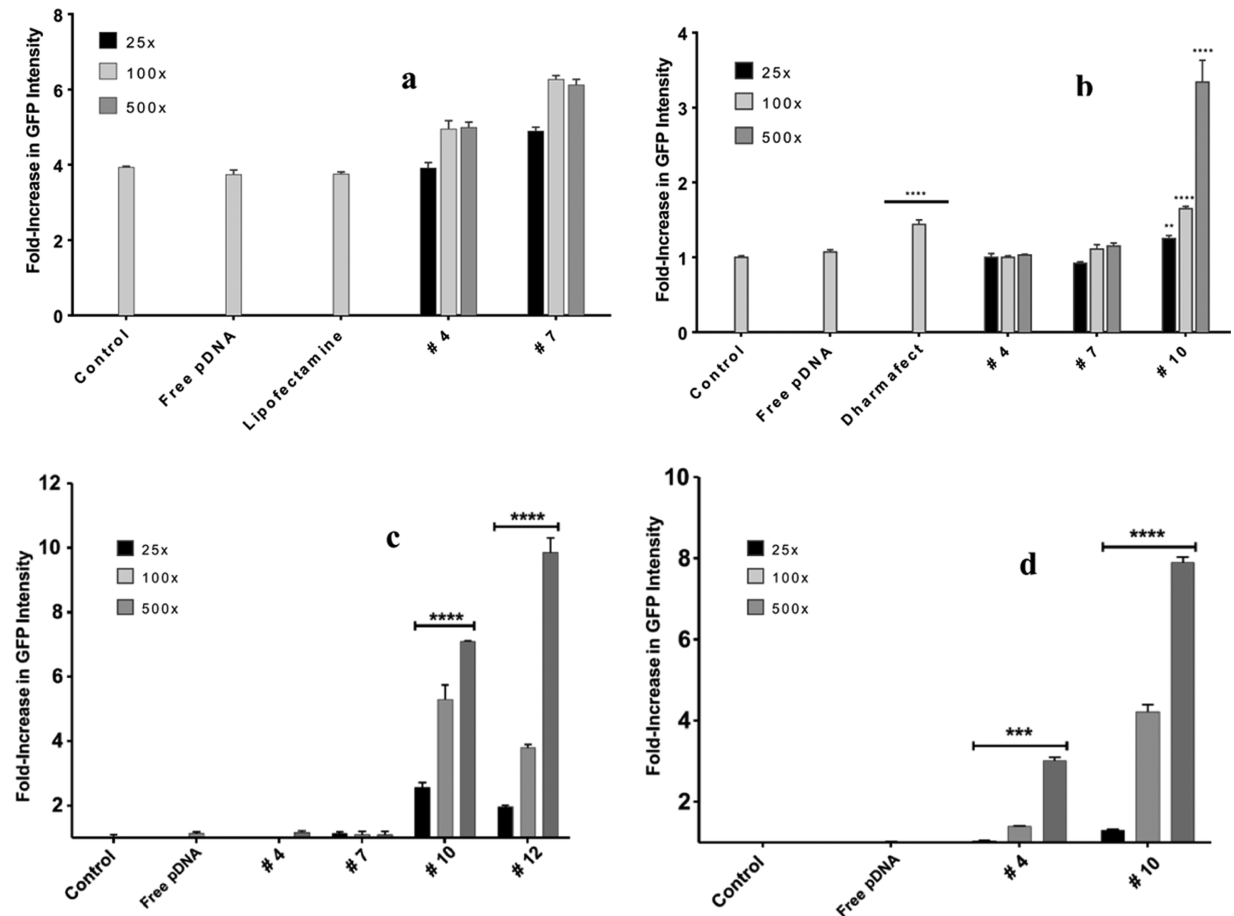

Figure 5. (a) HeLa, (b) 4T1, (c) NIH3T3 and (d) CCD 27SK cells analyzed for GFP expression after 48 h total transfection using flow cytometer: control- untreated cells, free pDNA used as a negative control, DharmaFECT and Lipofectamine-commercially available transfection agent. 25 $\times$, $100 \times, 500 \times$ are WRs of $\mathrm{CP} / \mathrm{pDNA}$. Flow-cytometry results indicate mean $\pm \mathrm{SD}, n=3,10000$ events/repetition, $1 \mu \mathrm{g}$ pDNA/30 000 cells. The CPs numbers corresponds to those given the Table 1 . All comparisons were performed against the no-treatment control. The error bars represent mean \pm $\mathrm{SD}, n=3(* * * P<0.005, * * * * P<0.0005)$

Table 4. Selective Transfection Activity of New CPs toward Certain Cell Lines

\begin{tabular}{cclcc} 
& \multicolumn{4}{c}{ transfection efficiency, \% } \\
\cline { 2 - 5 } CP sample \# & HeLa & 4T1 & NIH3T3 & CCD 27SK \\
4 & high & low & high & low \\
7 & high & low & $a$ & low \\
10 & $a$ & high & high & $a$ \\
11 & $a$ & $a$ & $a$ & high \\
12 & $a$ & $a$ & $a$ & high
\end{tabular}

${ }^{a}$ Not tested due to increased cytotoxicity toward these cell lines.

other, and our reported results strongly indicate the selective transfection ability profiles of the CPs tested. It should be noted that for complex gene delivery applications, there is no one-fitsall polymer/carrier type for variety of tissues and malignancies to be treated. However, our results indicate that the carefully selected CPs from a small library of polymers were able to provide all the required properties for different cell types as effective transfection agents. Hence, we believe that the new CPs have a potential for the applications in gene therapy and biotechnology as nontoxic and effective agents for intracellular delivery of nucleic acids.

\section{EXPERIMENTAL SECTION}

Materials. All chemicals were purchased from Sigma-Aldrich (St. Louis, MO, USA) unless otherwise stated. PEI $\left(M_{\mathrm{w}} 25 \mathrm{kDa}\right)$ was purchased from Polysciences, Inc. (Warrington, PA). The CellTiter-Blue Cell Viability Assay was obtained from Promega (Madison, WI, USA). Plasmid DNA-green fluorescence protein reporter gene ( $\mathrm{pEGFP-N1)}$ was produced and purchased from Elim Biopharmaceuticals, Inc. (Hayward, CA,
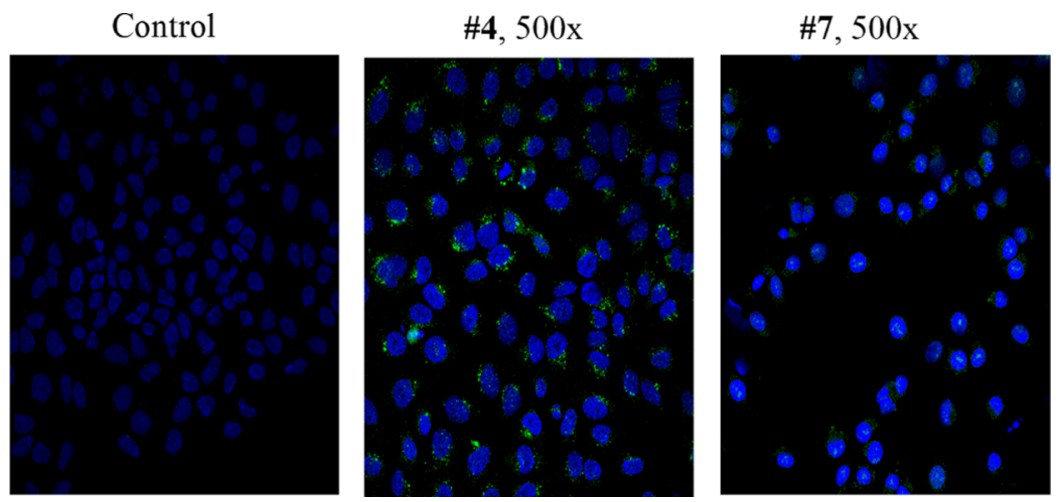

Figure 6. Confocal microscopy images of cellular interaction of different complexes with HeLa cells after $48 \mathrm{~h}$ incubation. 
USA). DNase I enzyme (1X) supplied with DNase I Buffer $(10 \times)$ and $50 \mathrm{mM}$ ethylenediaminetetraacetic acid (EDTA) were purchased from Fisher BioReagents (Pittsburgh, PA, US).

Cell Cultures. All cell lines 4T1 (murine mammary carcinoma), HeLa (human cervical adenocarcinoma), NIH3T3 (mouse fibroblast), and CCD 27SK cells (human fibroblast) were obtained from American Type Culture Collection (ATCC, Manassas, VA, USA) and were grown at $37{ }^{\circ} \mathrm{C}$ in 5\% CO and 95\% humidity in Dulbecco's modified Eagle's medium or in RPMI1640 (Gibco, Life Technologies, Carlsbad, CA, USA), supplemented with $10 \%$ heat-inactivated fetal bovine serum (Atlanta Biologicals, Flowery Branch, GA), $50 \mathrm{U} / \mathrm{mL}$ penicillin, and $50 \mu \mathrm{g} / \mathrm{mL}$ streptomycin (Corning/ Mediatech, Manassas, VA, USA). Whenever required, cells were harvested by trypsinization with $0.5 \%$ trypsin in phosphatebuffered saline (PBS) containing 0.25\% EDTA (Corning/ Mediatech, Manassas, VA, USA).

Methods. Synthesis of Monomers and Polymers. The synthesis of the polyamine-based polymers via the SAP followed three major steps:

(1) Preparation of key nucleophilic monomers-salts of polyamines such as tetra- $p$-toluenesulfonate and tetrahydrochloride of $\mathrm{Spm}$, and tri-p-toluenesulfonate and trihydrochloride of Apd labeled as SpmT4, SpmC4, ApdT3, and ApdC3, accordingly. A detailed procedure for preparing and the general characteristics of the salt monomers are provided in the Supporting Information.

(2) Synthesis of two classes of bis-electrophilic monomers: (i) two activated diesters of dicarboxylic acids-di- $p$-nitrophenyl succinate (NSu) and di-p-nitrophenyl-trans-epoxy succinate $(\mathrm{N} t \mathrm{ES})$ and (ii) one activated diester of carbonic acid-NC. Information about the synthetic and the basic characteristics of the activated diester monomers are provided in the Supporting Information.

(3) Synthesis of Spm and Apd-based polymers (Scheme 1) by polycondensation of $\mathrm{NC}, \mathrm{NSu}$, and $\mathrm{N} t \mathrm{ES}$ with bisnucleophilic salt monomers according to step 1 (see Scheme S3). The following polymers in forms of either $p$-toluenesulfonates or hydrochlorides were obtained: (i) PUs, and PAs-(ii) PSuAs and (iii) RPAs. The latter were obtained by the one-pot/two-step synthetic strategy-by polycondensation of $\mathrm{N} t \mathrm{ES}$ with the salt monomers at the step 1 , and by in situ interaction of intermediate EPAs with $\mathrm{RMeC}$ at the step 2 as depicted in Scheme S3. The details of the synthesis of these polymers are provided in the Supporting Information.

To avoid long polymer names, we introduce the following abbreviations for the three classes of polyamines-based polymers (Scheme 1):

For Spm and Apd-based PUs: 1SpmT, 1SpmC, 1ApdT, and $1 \mathrm{ApdC}$, where 1 corresponds to the carbonic acid residue (-CO-), T means $p$-toluenesulfonate, and $\mathrm{C}$ means chloride, accordingly.

For Spm and Apd-based PSuAs: 2SpmT, 2SpmC, 2ApdT, and $2 A p d C$, where 2 corresponds to the succinic acid residue, $\mathrm{T}$ means $p$-toluenesulfonate, and $\mathrm{C}$ means chloride, accordingly.

For Spm and Apd-based intermediate EPAs: ESpmT, ESpmC, EApdT, and EApdC, where E corresponds to the epoxy-succinic acid residue, $\mathrm{T}$ means $p$-toluenesulfonate, and $\mathrm{C}$ means chloride, accordingly.

For Spm and Apd-based RPAs with covalently attached $\mathrm{RMeC}$ : RSpmTC and RSpmCC means $\mathrm{RMeC}$ attached to the
Spm-based epoxy-PAs which were in either $p$-toluenesulfonate (ESpmT) or chloride (ESpmC) forms, accordingly. RApdTC and RApdCC means RMeC attached to Apd-based EPAs, which were in either $p$-toluenesulfonate (EApdT) or chloride (EApdC) forms, accordingly.

Characterization of Monomers and Polymers. The salt monomers were characterized by elemental analysis, melting points (Table S1), and ${ }^{1} \mathrm{H}$ NMR analysis (see Supporting Information); one of these salts-SpmC4 was reported in the literature and its melting point well coincided with reported data. The polyamines and their salts were expected to be hygroscopic. The hygroscopicity of the free base (Spm) and the salts SpmT4, SpmC4, ApdT3, and ApdC3 was assessed by weight gain under atmospheric conditions (see Figure S1). The chemical structure of the obtained new CPs was confirmed by NMR spectroscopy (see Supporting Information). The molecular weight characteristics of the new CPs were measured in HFIP (from Sigma), solution using a GPC machine (Shimadzu, model LC-8A) equipped with the LC solution V.1.25 SP2 software from Shimadzu. A PL HFIP gel column (Polymer Lab) and a refractive index detector (Shimadzu RID10A) were employed. The polymer was dissolved in and eluted with HFIP containing $\mathrm{CF}_{3} \mathrm{COONa}(0.05 \mathrm{M}$, to suppress polyelectrolyte effects). Injected volume: $100 \mu \mathrm{L}$, sample concentration: $2.0 \mathrm{mg} / \mathrm{mL}$, flow rate: $0.5 \mathrm{~mL} / \mathrm{min}$. The columns were calibrated with polymethylmethacrylate (PMMA) standards. The molecular weight characteristics of the CPs are given in Table 1.

In Vitro Cytotoxicity. 4T1, HeLa, NIH3T3, and CCD 27SK cells were seeded in 96-well plates at a density of $5 \times 10^{3}$ and $3 \times$ $10^{3}$ cells/well for 24 and $48 \mathrm{~h}$ cytotoxicity screening of the polymers, respectively. Twenty-four hours after seeding, the culture medium was replaced with fresh complete cell culture medium containing the various concentrations of polymers. Following 24 and $48 \mathrm{~h}$ continuous treatment with the newly synthesized polymers as well as polyethyleneimine (PEI), cell viability was assessed using CellTiter-Blue cell viability assay according to the manufacturer's protocol. The relative cell viability (\%) was calculated with cells treated only with the medium as a control.

Polyplex Formation. Polyplexes were prepared at different polymer/pDNA (pEGFP-N1) WR between 1 and 500 (designated as $1 \times, 5 \times, 25 \times, 100 \times$, and $500 \times$ ). Briefly, equal volumes of polymer solutions from the library and pDNA solution in Milli-Q water were mixed and vortexed for $10 \mathrm{~s}$. The mixtures were incubated at room temperature for $30 \mathrm{~min}$. Whenever sterile polyplexes are needed, the individual polymer and pDNA solutions were filtered through a $0.2 \mu \mathrm{m}$ sterile filters prior mixing and the following steps are carried out in a biosafety level 2 tissue culture cabinet. The samples were analyzed by gel electrophoresis on an ethidium bromide-stained E-Gel GP (0.8\%) (Invitrogen, Life Technologies) and after $30 \mathrm{~min}$ migration under $60 \mathrm{~V}$ pDNA bands were visualized by UV transillumination.

Protection from Nucleases. The ability of polymers to protect the pDNA from the DNase activity was also investigated. For the DNA digestion assay, the complexes of polymer/pDNA were incubated for $1 \mathrm{~h}$ at $37^{\circ} \mathrm{C}$ with $2 \mu \mathrm{L}$ of DNase I buffer and 1 $\mu \mathrm{L}$ DNase I enzyme in a $50 \mu \mathrm{L}$ reaction volume. The enzymatic reaction was terminated by addition of $10 \mu \mathrm{L} 50 \mathrm{mM}$ EDTA solution followed by incubation at $65{ }^{\circ} \mathrm{C}$ for $10 \mathrm{~min}$. For the release of pDNA from polyplexes, heparin (50 units/ $\mu \mathrm{g}$ of pDNA) was added and the mixtures were further incubated for 
$25 \mathrm{~min}$ at $37^{\circ} \mathrm{C}$. The samples were electrophoresed under the same conditions described previously to follow the integrity of pDNA.

Size and Zeta Potential Study of Complexes. The size and zeta potential of complexes were determined by the QELS using a Zeta Plus Particle Analyzer (Brookhaven Instruments Corp, Santa Barbara, CA) equipped with the Multi-Angle Option at an angle of $90^{\circ}$ at room temperature. Measurements were performed after diluting the samples with Milli-Q water and with count rates of approximately $100-400 \mathrm{kcps}$ for each sample. Average values were calculated from at least 10 runs.

Cellular Uptake of the Polymer/pDNA Complexes. Transfection experiments of selected CPs were carried out with 4T1, HeLa, NIH3T3, and CCD 27SK cells. In a typical experiment, 12 -well tissue culture plates were seeded with $30 \times 10^{3}$ cells/well in $1 \mathrm{~mL}$ of medium and incubated for $24 \mathrm{~h}$ prior to transfection. The polymer/pDNA complexes were prepared as described earlier. The cells were incubated with complexes in serum-free medium for $6 \mathrm{~h}$ at $37^{\circ} \mathrm{C}$. Naked pDNA was used as a negative control. Complexes obtained with DharmaFECT were used for comparison. After $6 \mathrm{~h}$ of incubation, the medium was removed, and cells were washed and incubated with $1 \mathrm{~mL}$ of the complete medium for additional $42 \mathrm{~h}$ to allow the expression of eGFP protein. After that the cells were washed, harvested by trypsinization, and centrifuged at $400 \mathrm{~g}$ for $5 \mathrm{~min}$. The cell pellets were rinsed once with cold PBS, resuspended in $300 \mu \mathrm{L}$ of cold PBS, and maintained on ice until the analysis. Data acquisition was performed on a Becton Dickinson FACScan flow cytometer (Becton Dickinson, San Jose, CA, USA) at the emission wavelength of $520 \mathrm{~nm}$ (channel FL-1). For each sample, cell debris and dead cells were gated out and 10000 alive cell counts were analyzed. Cell-associated fluorescence intensities were expressed as the average of these measurements $(n=3)$.

Confocal Microscopy Study. For confocal microscopy study, HeLa cells were seeded on coverslips (Fisher Scientific, Pittsburgh, PA, USA) at a density of $30 \times 10^{3}$ cells/well in 1 $\mathrm{mL}$ of RPMI and incubated for $24 \mathrm{~h}$ prior to transfection. Cells were treated with the polymer/pDNA complexes at WR of $25 \times$, $100 \times$ and $500 \times$, or with an equal amount of free aqueous solutions of polymers. After $6 \mathrm{~h}$ of incubation, the medium was removed, and cells were washed and incubated with $1 \mathrm{~mL}$ of the complete medium for additional $42 \mathrm{~h}$. At the end of the incubation period, the medium was removed, and cells were washed twice with PBS followed by the fixation of the cells with $1 \%(\mathrm{w} / \mathrm{v})$ paraformaldehyde in $\mathrm{PBS} \mathrm{pH} 7.4$ for $25 \mathrm{~min}$ at $37^{\circ} \mathrm{C}$. Then, cells were washed again with PBS once and incubated with Hoechst $33342(5 \mu \mathrm{M})$ containing PBS for $10 \mathrm{~min}$ at room temperature. A Zeiss LSM 700 confocal scanning laser microscope was used for imaging of the cells.

Statistical Analysis. Unless otherwise indicated, all results are presented as the mean \pm standard deviation (SD) calculated over at least three replicates. The data were analyzed using Prism 7 software (GraphPad); $P$-values less than 0.05 were considered to indicate a significant difference.

\section{ASSOCIATED CONTENT}

\section{S Supporting Information}

The Supporting Information is available free of charge on the ACS Publications website at DOI: 10.1021/acsomega.8b02977.

Methods and materials; experimental procedures; reaction schemes and details of characterization data including ${ }^{1} \mathrm{H}$ NMR spectra of all new monomers and CPs; the hygroscopic study of bisnucleophilic monomers depicted in the graph; and graphs of cytotoxicity results of CPs toward 4T1, HeLa, NIH3T3, and CCD 27SK cell lines (PDF)

\section{AUTHOR INFORMATION}

\section{Corresponding Authors}

*E-mail: v.torchilin@neu.edu. Phone: +1-6173733206 (V.P.T.).

*E-mail: r.katsarava@agruni.edu.ge. Phone: +995-599159209 (R.K.).

ORCID $\odot$

Nino Zavradashvili: 0000-0002-4607-1571

Giuli Otinashvili: 0000-0001-5451-3395

Tengiz Kantaria: 0000-0001-7376-6507

Davit Tugushi: 0000-0002-9827-5154

Ramaz Katsarava: 0000-0002-2373-1514

\section{Author Contributions}

All authors contributed equally to this work.

Notes

The authors declare no competing financial interest.

\section{ACKNOWLEDGMENTS}

The project depicted was sponsored by the Department of the Defense, Defense Threat Reduction Agency. The content of the information does not necessarily reflect the position or the policy of the federal government, and no official endorsement should be inferred (grant GRDF/CRDF Global \#A60694 SRNSF \#04/41).

\section{ABBREVIATIONS}

$\mathrm{CP}$, cationic polymer; PEI, polyethylenimine; R, L-arginine; Spm, spermine; Apd, $\mathrm{N}$-(2-aminoethyl)-1,3-propanediamine; PA, polyamide; PU, polyurea; PSuA, polysuccinamide; PRA, arginine-attached polyamide; SAP, solution active polycondensation; EPA, epoxy-polyamide; SpmT4, tetra- $p$-toluenesulfonate of spermine; SpmC4, tetrahydrochloride of spermine; ApdT3, tri-p-toluenesulfonate of $\mathrm{N}$-(2-aminoethyl)-1,3-propanediamine; ApdC3, trihydrochloride of $N$-(2-aminoethyl)-1,3propanediamine; NSu, di- $p$-nitrophenyl succinate; $\mathrm{N} t \mathrm{ES}$, di- $p$ nitrophenyl-trans-epoxy succinate; NC, di-p-nitrophenyl carbonate; $\mathrm{RMeC}$, arginine-methyl ester dihydrochloride; $1 \mathrm{SpmT}$, 1 SpmC, 1 ApdT, 1 ApdC, spermine and $N$-(2-aminoethyl)-1,3propanediamine based polyureas, where 1 corresponds to the carbonic acid residue ( $-\mathrm{CO}-)$, T means $p$-toluenesulfonate and C means chloride, accordingly; 2SpmT, 2SpmC, 2ApdT, 2ApdC, spermine and $N$-(2-aminoethyl)-1,3-propanediamine based polysuccinamides where 2 corresponds to the succinic acid residue, $\mathrm{T}$ means $p$-toluenesulfonate and $\mathrm{C}$ means chloride, accordingly; ESpmT, ESpmC, EApdT, EApdC, spermine and $\mathrm{N}$-(2-aminoethyl)-1,3-propanediamine based intermediate epoxy-polyamides where $\mathrm{E}$ corresponds to the epoxy-succinic acid residue, $\mathrm{T}$ means $p$-toluenesulfonate and $\mathrm{C}$ means chloride, accordingly; RSpmTC, RSpmCC, RApdTC, RApdCC, spermine and $N$-(2-aminoethyl)-1,3-propanediamine based polyamides with covalently attached arginine-methyl ester hydrochloride where RSpmTC and RApdTC are $p$-toluenesulfonates and RSpmCC and RApdCC are chlorides, accordingly; HFIP, hexafluoroisopropanol; PMMA, polymethylmethacrylate; DMA, dimethylacetamide; TEA, triethylamine; 4T1, murine 
mammary carcinoma; HeLa, human cervical adenocarcinoma; NIH3T3, mouse fibroblast; CCD 27SK cells, human fibroblast

\section{REFERENCES}

(1) Samal, S. K.; Dash, M.; Van Vlierberghe, S.; Kaplan, D. L.; Chiellini, E.; van Blitterswijk, C.; Moroni, L.; Dubruel, P. Cationic polymers and their therapeutic potential. Chem. Soc. Rev. 2012, 41, $7147-7194$.

(2) Moroson, H.; Rotman, M. Biomedical Applications of Polycations. In Charged and Reactive Polymers: Polyelectrolytes and Their Applications; Rembaum, A., Sélégny, E., Eds.; Springer, 1975; Vol. 2, pp 187-195.

(3) Whitehead, K. A.; Langer, R.; Anderson, D. G. Knocking down barriers: advances in siRNA delivery. Nat. Rev. Drug Discovery 2009, 8, 129-138.

(4) Gao, X.; Kim, K.-S.; Liu, D. Nonviral Gene Delivery: What we know and what is next. AAPS J. 2007, 9, E92-E104.

(5) Uchida, E.; Mizuguchi, H.; Ishii-Watabe, A.; Hayakawa, T. Comparison of the efficiency and safety of non-viral vector-mediated gene transfer into a wide range of human cells. Biol. Pharm. Bull. 2002, 25, 891-897.

(6) Tiera, M.; Winnik, F.; Fernandes, J. Synthetic and Natural Polycations for Gene Therapy: State of the Art and New Perspectives. Curr. Gene Ther. 2006, 6, 59-71.

(7) Modra, K.; Dai, S.; Zhang, H.; Shi, B.; Bi, J. Polycation-mediated gene delivery: Challenges and considerations for the process of plasmid DNA transfection. Eng. Life Sci. 2015, 15, 489-498.

(8) Tiera, M. J.; Shi, Q.; Winnik, F. M.; Fernandes, J. C. Polycationbased gene therapy: current knowledge and new perspectives. Curr. Gene Ther. 2011, 11, 288-306.

(9) Beyerle, A.; Kissel, T.; Stoeger, T. Toxicity of Polymeric-Based Non-Viral Vector Systems for Pulmonary siRNA Application. NonViral Gene Ther. 2011, 20, 481-498.

(10) Pack, D. W.; Hoffman, A. S.; Pun, S.; Stayton, P. S. Design and development of polymers for gene delivery. Nat. Rev. Drug Discovery 2005, 4, 581-593.

(11) Luo, D.; Saltzman, W. M. Synthetic DNA delivery systems. Nat. Biotechnol. 2000, 18, 33-37.

(12) Rudolph, C.; Lausier, J.; Naundorf, S.; Müller, R. H.; Rosenecker, $\mathrm{J}$. In vivo gene delivery to the lung using polyethylenimine and fractured polyamidoamine dendrimers. J. Gene Med. 2000, 2, 269-278.

(13) van der Aa, M. A. E. M.; Huth, U. S.; Häfele, S. Y.; Schubert, R.; Oosting, R. S.; Mastrobattista, E.; Hennink, W. E.; Peschka-Süss, R.; Koning, G. A.; Crommelin, D. J. A. Cellular uptake of cationic polymerDNA complexes via caveolae plays a pivotal role in gene transfection in COS-7 cells. Pharm. Res. 2007, 24, 1590-1598.

(14) D'Andrea, C.; Pezzoli, D.; Malloggi, C.; Candeo, A.; Capelli, G.; Bassi, A.; Volonterio, A.; Taroni, P.; Candiani, G. The study of polyplex formation and stability by time-resolved fluorescence spectroscopy of SYBR Green I-stained DNA. Photochem. Photobiol. Sci. 2014, 13, 16801689.

(15) Ahmed, M.; Bhuchar, N.; Ishihara, K.; Narain, R. Well-controlled cationic water-soluble phospholipid polymer-DNA nanocomplexes for gene delivery. Bioconjugate Chem. 2011, 22, 1228-1238.

(16) Morgan, D. M. Polyamins: An introduction. In Polyamine Protocols; Morgan, D. M., Ed.; Methods inMolecular Biology; Humana Press, Inc.: Totowa, New Jersey, 1998; Vol. 79, pp 3-30.

(17) Maslov, M. A.; Kabilova, T. O.; Petukhov, I. A.; Morozova, N. G.; Serebrennikova, G. A.; Vlassov, V. V.; Zenkova, M. A. Novel cholesterol spermine conjugates provide efficient cellular delivery of plasmid DNA and small interfering RNA. J. Controlled Release 2012, 160, 182-193.

(18) Gagnon, K. T.; Watts, J. K.; Pendergraff, H. M.; Montaillier, C.; Thai, D.; Potier, P.; Corey, D. R. Antisense and antigene inhibition of gene expression by cell-permeable oligonucleotide-oligospermine conjugates. J. Am. Chem. Soc. 2011, 133, 8404-8407.

(19) Shim, M. S.; Kwon, Y. J. Dual mode polyspermine with tunable degradability for plasmid DNA and siRNA delivery. Biomaterials 2011, 32, 4009-4020.
(20) Zhang, H.; Vinogradov, S. V. Short biodegradable polyamines for gene delivery and transfection of brain capillary endothelial cells. J. Controlled Release 2010, 143, 359-366.

(21) Xu, R.; Lu, Z.-R. Design, synthesis and evaluation of sperminebased $\mathrm{pH}$-sensitive amphiphilic gene delivery systems: Multifunctional non-viral gene carriers. Sci. China: Chem. 2011, 54, 359-368.

(22) Jiang, H.-L.; Hong, S.-H.; Kim, Y.-K.; Islam, M. A.; Kim, H.-J.; Choi, Y.-J.; Nah, J.-W.; Lee, K.-H.; Han, K.-W.; Chae, C.; Cho, C.-S.; Cho, M.-H. Aerosol delivery of spermine-based poly(amino ester)/ Akt1 shRNA complexes for lung cancer gene therapy. Int. J. Pharm. 2011, 420, 256-265.

(23) Kim, Y.-K.; Cho, C.-S.; Cho, M.-H.; Jiang, H.-L. Spermine-altpoly(ethylene glycol) polyspermine as a safe and efficient aerosol gene carrier for lung cancer therapy. J. Biomed. Mater. Res., Part A 2013, 102, 2230-2237.

(24) Hosseinkhani, H.; Azzam, T.; Tabata, Y.; Domb, A. J. Dextranspermine polycation: an efficient nonviral vector for in vitro and in vivo gene transfection. Gene Ther. 2004, 11, 194-203.

(25) Abedini, F.; Ismail, M.; Hosseinkhani, H.; Ibrahim, T. A. T.; Omar, A. R.; Chong, P. P.; Bejo, M. H.; Domb, A. J. Effects of CXCR4 siRNA/dextran-spermine nanoparticles on CXCR4 expression and serum LDH levels in a mouse model of colorectal cancer metastasis to the liver. Cancer Manage. Res. 2011, 3, 301-309.

(26) Firouzamandi, M.; Moeini, H.; Hosseini, D.; Bejo, M. H.; Omar, A. R.; Mehrbod, P.; El Zowalaty, M.; Webster, T.; Ideris, A. Preparation, characterization, and in vivo vaccination of dextran-spermine nanoparticle DNAvaccine coexpressing the fusion and hemagglutinin genes against Newcastle disease. Int. J. Nanomed. 2016, 11, 259-267.

(27) Aziz, S. M.; Gosland, M. P.; Crooks, P. A.; Olson, J. W.; Gillespie, M. N. A Novel Polymeric Spermine Conjugate Inhibits Polyamine Transport in Pulmonary Artery Smooth Muscle Cells. J. Pharmacol. Exp. Ther. 1995, 274, 181-186.

(28) Gosland, M. P.; Gillespie, M. N.; Tsuboi, C. P.; Tofiq, S.; Olson, J. W.; Crooks, P. A.; Aziz, S. M. Reversal of doxorubicin, etoposide, vinblastine, and taxol resistance in multidrug resistant human sarcoma cells by a polymer of spermine. Cancer Chemother. Pharmacol. 1996, 37, 593-600.

(29) Du, Z.; Jin, T.; Huang, L. Polycation capable of being degraded into spermine, and synthesis method and nanoparticles thereof. Chinese patent application CN1025 6534 A, June 27, 2012.

(30) Duan, S.; Ge, X.; Lu, N.; Wu, F.; Yuan, W.; Jin, T. Synthetic polyspermine imidazole-4,5-amide as an efficient and cytotoxicity-free gene delivery system. Int. J. Nanomed. 2012, 7, 3813-3822.

(31) Kezdy, F.; Bruylants, A. Etude cinetique de l'hydrolyse des amides aliphatiques V. Hydrolyse alcaline de la succinimide et de la succinamide. Bull. Soc. Chim. Belg. 1960, 69, 602-615.

(32) Cohen, T.; Lipowitz, J. Acid catalyzed amide hydrolysis assisted by neighboring amide group. J. Am. Chem. Soc. 1964, 86, 5611-5616.

(33) Calvaresi, M.; Rinaldi, S.; Arcelli, A.; Garavelli, M. Computational DFT Investigation of Vicinal Amide Group Anchimeric Assistance in Ether Cleavage. J. Org. Chem. 2008, 73, 2066-2073.

(34) Ryser, H. J.-P.; Hancock, R. Histones and basic poly(amino acid)s stimulate the uptake of albumin by tumor cells in culture. Science $1965,150,501-503$.

(35) Holowka, E. P.; Sun, V. Z.; Kamei, D. T.; Deming, T. J. Polyarginine segments in block copolypeptides drive both vesicular assembly and intracellular delivery. Nat. Mater. 2006, 6, 52-57.

(36) Rothbard, J.; Jessop, T.; Wender, P. Adaptive translocation: the role of hydrogen bonding and membrane potential in the uptake of guanidinium-rich transporters into cells. Adv. Drug Delivery Rev. 2005, 57, 495-504.

(37) Futaki, S. Membrane-permeable arginine-rich peptides and the translocation mechanisms. Adv. Drug Delivery Rev. 2005, 57, 547-558.

(38) Brooks, H.; Lebleu, B.; Vives, E. Tat peptide-mediated cellular delivery: back to basics. Adv. Drug Delivery Rev. 2005, 57, 559-577.

(39) Torchilin, V. P. Recent approaches to intracellular delivery of drugs and DNA and organelle targeting. Annu. Rev. Biomed. Eng. 2006, $8,343-375$. 
(40) Yamanouchi, D.; Wu, J.; Lazar, A. N.; Kent, K. C.; Chu, C.-C.; Liu, B. Biodegradable arginine-based poly(ester-amide)s as non-viral gene delivery reagents. Biomaterials 2008, 29, 3269-3277.

(41) Memanishvili, T.; Zavradashvili, N.; Kupatadze, N.; Tugushi, D.; Gverdtsiteli, M.; Torchilin, V. P.; Wandrey, C.; Baldi, L.; Manoli, S. S.; Katsarava, R. Arginine-Based Biodegradable Ether-Ester Polymers with Low Cytotoxicity as Potential Gene Carriers. Biomacromolecules 2014, $15,2839-2848$.

(42) Turnell, W. G.; Cruz-Aranda, G. A.; Wu, M. M.-Z.; Chantung, R. L.; Gomurashvili, Z. D.; DeFife, K. M. Cationic alpha-amino acidcontaining biodegradable polymer gene transfer compositions. U.S. Patent 0,068,743 Al, March 12, 2009.

(43) Zavradashvili, N.; Memanishvili, T.; Kupatadze, N.; Baldi, L.; Shen, X.; Tugushi, D.; Wandrey, C.; Katsarava, R. Advances in Experimental Medicine and Biology: Infectious Diseases and Nanomedicine I; Adhikari, R., Thapa, S., Eds.; Springer: New Delhi, 2014; Vol. 807, pp 59-73.

(44) Katsarava, R. Active Polycondensation - from peptide chemistry to amino acid based biodegradable polymers. Macromol. Symp. 2003, 199, 419-430.

(45) Katsarava, R.; Gomurashvili, Z. Handbook of Biodegradable Polymers-Isolation, Synthesis, Characterization and Applications; Lendlein, A., Sisson, A., Eds.; Wiley-VCH: Weinheim, Germany, 2011; Chapter 5, pp 107-131.

(46) Katsarava, R. D.; Kartvelishvili, T. M.; Japaridze, N. N.; Goguadze, T. A.; Khosruashvili, T. A.; Tiger, R. P.; Berlin, P. A. Synthesis of polyureas by polycondensation of diamines with active derivatives of carbonic acid. Makromol. Chem. 1993, 194, 3209-3228.

(47) Katsarava, R. D.; Kharadze, D. P.; Avalishvili, L. M. Synthesis of high-molecular-weight polysuccinamides by polycondesation of active succinates with diamines. Makromol. Chem. 1986, 187, 2053-2062.

(48) Zavradashvili, N.; Jokhadze, G.; Gverdtsiteli, M.; Otinashvili, G.; Kupatadze, N.; Gomurashvili, Z.; Tugushi, D.; Katsarava, R. Amino Acid Based Epoxy-Poly(Ester Amide)s - a New Class of Functional Biodegradable Polymers: Synthesis and Chemical Transformations. J. Macromol. Sci., Part A: Pure Appl.Chem. 2013, 50, 449-465.

(49) Kobauri, S.; Otinashvili, G.; Kantaria, T.; Tugushi, D.; Kharadze, D.; Kutsiava, N.; Puiggali, J.; Katsarava, R. New amino acid based biodegradable polymers via bis-azlactone chemistry. J. Macromol. Sci., Part A: Pure Appl.Chem. 2018, in press. DOI: 10.1080/ 10601325.2018.1513776

(50) Lv, H.; Zhang, S.; Wang, B.; Cui, S.; Yan, J. Toxicity of cationic lipids and cationic polymers in gene delivery. J. Controlled Release 2006, 114, 100-109.

(51) Bottega, R.; Epand, R. M. Inhibition of Protein Kinase C by Cationic Amphiphiles. Biochemistry 1992, 31, 9025-9030.

(52) Yingyongnarongkul, B.-e.; Howarth, M.; Elliott, T.; Bradley, M. Solid-Phase Synthesis of 89 Polyamine-Based Cationic Lipids for DNA Delivery to Mammalian Cells. Chem.-Eur. J. 2004, 10, 463-473. 